\title{
Electron Backscatter Diffraction Analysis of a Reconstructed Wootz Damascus Steel Blade
}

\section{A.P. Sullivan,* M.R. Barnett, *}

* Centre for Fibre and Materials Innovation, Deakin University, Pigdons Road, Waurn Ponds, Victoria, Australia, 3217

The historical impact and subsequent fame of wootz weaponry in the ancient world has created interest in what has come to be seen as an advanced material even by modern standards. Ancient wootz artifacts are classed as high carbon (hypereutectoid) crucible steels and are characterised by high strength, hardness and wear resistance, but especially by their attractive surface pattern. The ingots used to make wootz implements are known to have been cast in India from as early as 300 BC, continuing into the 1700's, at which time the casting and forging knowledge declined and was eventually lost. No detailed written records exist of the forging methods used to make weapons and implements from cast wootz ingots [3], leading to numerous duplication methods. Recent attempts have ranged from good approximations to almost identical reproductions $[1,4,7,8]$. Notably absent from historical accounts are details of forging temperature, cooling rates, and the strains imparted at each forging step. This has until recently prevented modern attempts to 'rediscover' the ancient blacksmiths' method in which hot shortness during forging and duplication of the surface pattern are known obstacles. Hot shortness has largely been solved by spherodising the proeutectoid cementite (coarse carbide) at just above the A1. Duplication of the surface pattern has been more difficult, with the mechanism being disputed $[1,4,5,6]$. Debate over the origin and development of coarse carbide bands continues and EBSD analysis offers a new way of interpreting these complex microstructures. This study employs EBSD to investigate and identify relationships between carbide microstructure and thermomechanical history by measurement of crystal orientation and distribution for the primary phases (ferrite and carbide).

The microstructure of a reconstructed blade was examined by EBSD as indicated in Figure 1. Carbide banding was detected and an orientation clustering phenomena was observed within these bands similar to that known to occur in authentic wootz blades [2] (Figure 2). The clustering is evidenced by neighbouring particles in one band having the same or similar Euler colour. The carbide phase also showed a strong $<010>$ texture as indicated by a crystallographic pole figure (Figure 3). It is proposed that both of these characteristics are the result of the thermomechanical history of the blade in which the as-cast carbides remain undissolved throughout forging, but undergo extensive fragmentation and realignment. Minor dissolution effects are accounted for by a fine carbide dispersion observed throughout the ferrite matrix. The observed texture corresponds with the direction of the forging hammer blows.

The importance of cementite in the microstructure has subsequently focused the authors' attention on the deformation mechanisms of this phase. In particular, which slip planes are activated during plastic deformation of the bulky carbides that form the surface banding. 


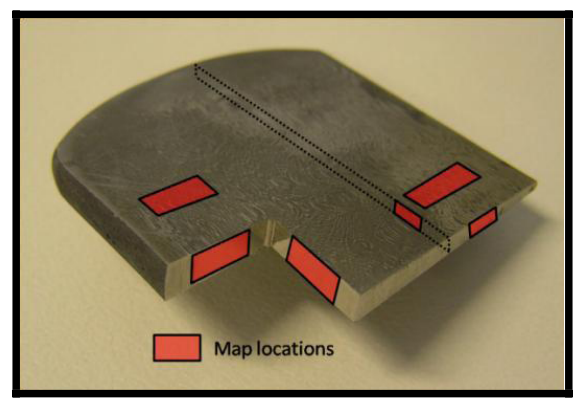

Figure 1. EBSD sampling locations in a reconstructed wootz blade [9].

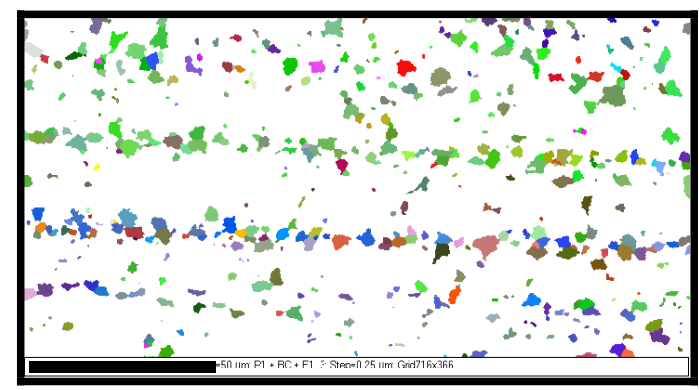

Figure 2. EBSD map showing carbide orientation distribution by colour scaled Euler angle. Scale bar $=50 \mu \mathrm{m}$.

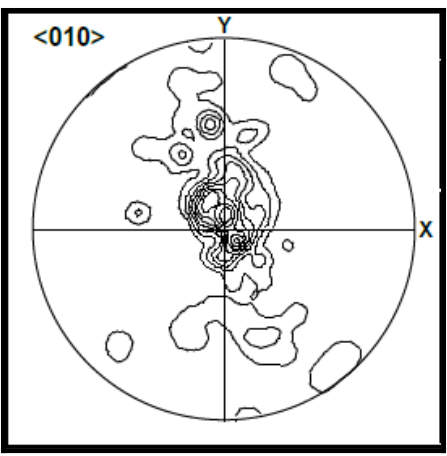

Figure 3. Pole figure showing a $<010>$ texture in the course carbide population in Figure 2.

References

1. J.D. Verhoeven, A.H. Pendray, and W.E. Dauksch, The Key Role of Impurities in Ancient Damascus Steel Blades, JOM, 50 (9) (1998), pp. 58-64.

2. A.Sullivan, M.Barnett, R.Balasubramaniam, Preliminary EBSD Analysis of Wootz Steel, Conference Proceedings, Microscopy \& Microanalysis 13(Suppl 2), 2007: 1104 CD.

3. O.D. Sherby, Ultrahigh Carbon Steels, Damascus Steels and Ancient Blacksmiths, ISIJ International, Vol.39 (1999), No.7, pp.637-648.

4. E.M. Taleff, B.L. Bramfitt, C.K. Syn, D.R. Lesuer, J. Wadsworth, O.D. Sherby, Processing, structure, and properties of a rolled, ultrahigh-carbon steel plate exhibiting a damask pattern, Materials Characterization, 46 (2001), 11-18.

5. J. Wadsworth, Response to Verhoeven comments on Damascus steel (correspondence), Materials Characterization, 47 (2001) 163-165.

6. J.D. Verhoeven, H.H. Baker, D.T. Peterson, H.F. Clark, W.M. Yater, Damascus Steel, Part III: The Wadsworth-Sherby Mechanism, Materials Characterization 24:205-227 (1990).

7. J. Perttula, Reproduced wootz Damascus steel, Scandinavian Journal of Metallurgy (2001); 30:2:65-68.

8. A.H. Pendray, How to make a Damascus blade, Scientific American, Jan (2001).

9. The sample material used in this work was kindly provided by Distinguished Emeritus Professor John D. Verhoeven of Iowa State University. 